\title{
Muscle Tone Score
}

National Cancer Institute

\section{Source}

National Cancer Institute. Muscle Tone Score. NCI Thesaurus. Code C81312.

A component of the Apgar score, it is the numerical value assigned to an assessment of the residual muscle tension of a neonate. 0 = flaccid; 1 = flexion of extremities; 2 = active motion. 